\title{
O GOVERNO MORAL DOS POBRES E A DESPOLITIZAÇÃO DAS POLÍTICAS PÚBLICAS NA AMÉRICA LATINA ${ }^{1}$
}

\author{
Bruno Lautier*
}

\begin{abstract}
O texto tem como ponto de partida a ideia de que a América Latina viveria nas últimas duas décadas uma tensão entre dois discursos, visões de mundo e formas de fazer sociedade: por um lado a constatação de disfunções a serem corrigidas e, por outro lado, as reivindicações e exigências em nome da cidadania, dos direitos, de sua universalização. A hipótese é a de que essa tensão - amenizada mas não extinta - e seu desenrolar, guardam fortes relações com a concepção, instituição, gestão, operacionalização de políticas sociais em um percurso que vai do enfoque desenvolvimentista aos processos de focalização, dos direitos ao governo moral da pobreza e seus desdobramentos.
\end{abstract}

Palavras-chave: Políticas sociais. Direitos. Cidadania. América Latina. Moral.

Toda a América Latina vive, há 20 anos, em uma tensão entre dois discursos sobre os pobres e a pobreza, duas visões de mundo e talvez dois modos de fazer sociedade. De um lado, podem-se encontrar um discurso e uma visão simultaneamente racionais e impulsionados por sentimentos: constata-se uma série de disfunções - pobreza, carências, corrupção, falta de serviços públicos, etc. - e há certa aflição sobre esse estado: mobilizam-se recursos para corrigi-lo, refinam-se técnicas para remediá-lo. De outro lado, há uma multiplicação de discursos que falam de outra coisa, não daquilo que é, mas daquilo que se reivindica, que se exige. As palavras empregadas são "cidadania"

\footnotetext{
* Sociólogo. Foi professor de sociologia da Universidade Panthéon Sorbonne, tendo defendido seu doutoramento em 1974 na Universidade de Amiens em Ciências Econômicas e em Sociologia. Foi diretor do IEDES-Paris I (Institut d'Etude du Développement Economique et social), de 2001 a 2006. Dirigiu ainda o mestrado em Desenvolvimento Social: Trabalho, Formação e Saúde (Développement social: travail, formation, santé) desde 2005 até sua morte.

${ }^{1}$ Este texto foi publicado pela primeira vez em Lautier, B. 2009 "Gouvernement moral des pauvres et dépolitisation des politiques publiques en Amérique latine". In: BorgeaudGarciandía N., Lautier, B., Peñafiel, R., Tizziani, A. (dir.), Penser le politique en Amérique latine: la recréation des espaces et des formes du politique, Paris, Karthala, p. 19-36. O texto pôde ser traduzido graças à amável autorização da editora Karthala. Tradução por Cibele Saliba Rizek.
}

e "direitos", e o discurso é o da universalidade. As políticas públicas contemporâneas têm por responsabilidade não apenas eliminar essa tensão, mas torná-la suportável, geri-la. Face à denotação de exclusão, tais políticas não estão engajadas na via de um "inclusive liberalism"1 (Porter; Craig, 2004). O liberalismo está mal arregimentado para incluir, a não ser "caso a caso", já que a reivindicação de cidadania, por definição, não é individual. A questão é, então, a de saber se uma imensa multiplicidade de técnicas e táticas em operação conseguiu conter a "tensão" que é constitutiva do político.

A hipótese subjacente a este texto é a de que a tensão política é efetivamente contida, mas não extinta, e, talvez, a de que essa mesma tensão acabe por se tornar tanto mais explosiva quanto mais sua contenção tenda a exacerbá-la, em vez de desativá-la. Existem, entretanto, válvulas de segurança que implicam concessões à concepção assentada nos direitos sociais do cidadão: certas passagens da Constituição brasileira de 1988 e diversas leis que foram aprovadas em seguida, como a Lei Or${ }^{1}$ Em inglês, no original. 
gânica da Assistência Social (LOAS) de 1993); há, ainda, a "Lei 100", que instaura um acesso universal à saúde na Colômbia em 1993, e os diversos Conditional Cash Transfer Programs (CCTP), ${ }^{2}$ no México, na Argentina, no Chile, no Brasil e na Colômbia, cujo próprio título indica que foram promovidos para se contrapor a uma reivindicação pautada pelos termos dos direitos incondicionais do cidadão a participar da riqueza da nação. Essas válvulas e suas concessões parecem estar na contramão da operacionalização e da prática, que acabam por se contrapor a esses mesmos direitos sociais.

Até o momento presente, essas válvulas estão em funcionamento, e a tensão não foi dissipada. Mas sua contenção só pôde ser feita pagando o preço de variações consideráveis nas táticas de governo, as quais este texto se propõe a rastrear. Para fazê-lo, passarei por uma breve recuperação histórica do período "desenvolvimentista”, até os anos oitenta (ponto 1), para, em seguida, fazer algumas observações sobre a passagem da "ultrafocalização" à "focalização ampla" no final dos anos noventa (ponto 2) e terminar com observações sobre o consenso que caracterizaria as políticas sociais atuais e que parece conter um mal entendido (ponto 3)

\section{AS "TÁTICAS DE GOVERNO” NO ज़ PERÍODO DESENVOLVIMENTISTA}

Há uma grande tradição de análise das políticas públicas na América Latina. Geralmente, dos anos 50 ao final dos anos oitenta, a concepção dominante de políticas públicas estava intimamente ligada à ideia de desenvolvimento, isto é, a um processo de transformação econômica e social conduzida por um sujeito: o Estado. As políticas públicas não seriam "públicas" somente pelo lugar (institucional) a partir do qual foram conduzidas; seriam, antes de tudo, uma modalidade - e uma modalidade até mesmo essencial - da relação entre Estado

Programas de transferência de renda condicionada. Em inglês, no original. e sociedade. Essas políticas seriam propriamente "públicas", não só porque dizem respeito aos meios de ação do Estado sobre o espaço público, mas porque "publicizariam" seu objeto, já que, ao retirá-lo da esfera privada, poderiam projetá-lo na esfera pública, fazendo-os objetos legítimos de intervenção do Estado e tornando-os, assim, objetos "públicos".

As políticas públicas "desenvolvimentistas” se apresentavam explicitamente como políticas de conformação do corpo social, por acréscimos sucessivos (na forma de transplantes) a esse corpo nacional, de órgãos que tinham sido simultaneamente engendrados; assim, tais políticas não se originavam por um compromisso entre "atores" constituídos (Lautier, 1993). O corporativismo de Estado não era, então, uma "disfunção" ou uma patologia, mas um elemento essencial das políticas públicas. $\mathrm{O}$ que ficava à margem desse corpo social permanentemente em gênese, o que transbordava, o que não se encaixava nessa conformação, devia ser eliminado, eventualmente com extrema violência.

Essa "conformação" do corpo social é, concomitantemente, o objetivo primeiro das políticas particulares (as policies, no sentido anglo saxão) e da articulação central da política (sempre no sentido anglo saxão - politics - de conflitos, compromissos, coalizões para a conquista e o exercício do poder). Essa ambivalência do substantivo "político" está constantemente presente nas análises dos pesquisadores latino-americanos até o final dos anos oitenta. Quando se falava de "políticas públicas", fazia-se imediatamente alusão às políticas (policies) precisas: política agrícola, política industrial, política de câmbio, de saúde, de educação, etc. Mas, paralelamente, afirmavase o caráter político (politics) dessas políticas: por exemplo, o laço entre um sistema contributivo de proteção social e o corporativismo sindical foi constantemente indicado (e muitas vezes deplorado); a política de localização dos investimentos públicos era geralmente interpretada como um instrumento de formação de 
alianças com os caciques locais; uma política de câmbio seria analisada como a base de um rearranjo de compromissos políticos com o patronato de tal ou tal setor; as políticas de subvenção aos produtos de base foram analisadas como instrumentos de um clientelismo de Estado, por oposição às políticas de distribuição em natura, que davam lugar principalmente para um clientelismo local, etc.

No que concerne especificamente às políticas que se destinavam aos pobres no período "desenvolvimentista", a intervenção do Estado acentua uma tática empírica de regulação (Lautier, 1995). A pobreza é útil (ela permite a submissão da multidão ao favor, como modo de dominação privilegiado dos pobres), ainda que, demais, ela seja portadora de perigos (perigos reais, como revoltas e criminalidade, assim como simbólicos, como a degradação da imagem do poder público). A “regulação” deveria ser compreendida, em seu sentido imediato, como política que tangencia a tentativa e o erro, como um "nem muito nem pouco" que repousaria sobre uma combinatória das três matrizes simbólicas e práticas (os modelos assistencial-repressivo, modernista-tecnocrático e filantrópico). Era, antes de tudo, a massa dos pobres que estaria sendo controlada e regulada, e não o corpo individual dos pobres; as técnicas de repressão seriam as técnicas de massa, que pertenceriam mais às habilidades do bombeiro do que as do policial (os pobres saqueiam, se revoltam, envia-se o exército para sua contenção e o estouro rapidamente se esvazia). Para além dessas fases de efervescência ${ }^{3}$ o controle dos pobres se assentava sobre o favor privado individualizado, essa "dívida inextinguível", ${ }^{4}$ e não apenas sobre o contrato e o compromisso coletivos.

3 Uma afirmação de Jacques Rancière é esclarecedora:
"Isso passa ou se estilhaça, dizem voluntariamente nossas
elites, confrontadas com a má vontade das massas. Falta
muito pouco para que se estilhace”. Em francês: "Ça passe
ou ça casse, disent volontiers nos élites, confrontées au
mauvais vouloir des masses. Seulement, il en faut très peu
pour que ça casse" (2005a).
${ }^{4}$ Dívida essa que, de acordo com Christian Geffray (1995), é o fundamento da relação paternalista.
Se nos referimos à noção de Foucault, segundo a qual são as táticas de governo que permitem, a cada instante, definir o que deve e o que não deve ganhar relevância para o Estado, definir o que é público e o que é privado,5 parece que, durante quatro décadas, o coração dessas táticas voltadas para as políticas frente aos pobres foi o de "privatizar o público".

O paradoxo que se coloca, então, advém do fato de que o Estado foi apresentado, nesse período, como fortemente intervencionista do ponto de vista social. Entretanto, exceto para algumas políticas particulares realmente "públicas" e manifestadamente destinadas aos pobres (como as políticas de subvenção a produtos de primeira necessidade), esse intervencionismo estatal foi apenas e tão somente falsamente "público", já que pressupunha mediações privadas (caciques, personagens clientelistas, etc.), ou seja, praticamente se entregam, nas mãos de personagens e políticos clientelistas, os meios públicos de regulação da pobreza.

\section{O GOVERNO FOCALIZADO DOS POBRES: da ultrafocalização à foca- lização ampla}

Desde o final dos anos oitenta, uma mudança do "regime de governabilidade" vem operando sobre cada um desses elementos. Essa mudança tem muitas facetas, sendo que a mais importante, a mais visível, é a focalização ou as políticas de luta contra a pobreza que se dirigem a públicos-alvo. Todas essas políticas,

${ }^{5}$ Na conclusão do texto "La gouvernementalité" (1994a), Michel Foucault escreveu: "sã̃o as táticas de governo que permitem a cada instante definir o que deve e o que não deve ter relevância para o Estado, o que é público e o que privado, o que é e o que não é do âmbito do estado estatal. Assim, se vocês quiserem, o Estado em sua sobrevivência e o Estado nos seus limites não devem se compreender senão a partir de táticas gerais de governabilidade. Em francês, conforme original: "ce sont les tactiques de gouvernement qui permettent à chaque instant de définir ce qui doit relever de l'Etat et ce qui doit pas en relever, ce qui est public et ce qui est privé, ce qui est étatique et ce qui est non étatique. Donc, si vous voulez, l'État dans sa survie et l'État dans ses limites ne doivent se comprendre qu'à partir des tactiques générales de la gouvernementalité” (p. 656). 
a priori, constituem um objeto privilegiado para o pesquisador, particularmente se ele tem uma inspiração neofoucaultiana, ou se houver alguma proximidade entre essas políticas e o "governo da miséria" na França da primeira metade do século XIX:

- Aí se encontram todas as características (métodos, objetivos, efeitos) da distinção entre os "bons pobres" (ou "pobres envergonhados") e "maus pobres" (Procacci, 1993, p. 209). O "bom pobre" aceita a inquirição (sobre sua renda real, já que o mau pobre é um dissimulador, sobre o modo de vida, já que o mau pobre é cheio de vícios, etc.) e, ao mesmo tempo, admite facilmente que deve ser reeducado. É franco (deve ser manifestadamente pobre e "inspirar piedade") e deve ser, simultaneamente, humilde. O mau pobre considera a ajuda assistencial como uma obrigação e recusa a existência de contrapartidas a essa ajuda (inclusive e sobretudo do tipo workfare).

- Aí se encontra, funcionando plenamente, a dualidade moralização e tecnicização. As políticas focalizadas devem ser supostamente motivadas pela aflição e pela indignação. ${ }^{6}$ Tais políticas não foram suscitadas pela pobreza, mas pelo espetáculo dos pobres: a moral não parece poder atuar senão na contramão dos indivíduos concretos e dignos de compaixão (crianças mal alimentadas em idade escolar ou cortadores manuais de cana, catadores de resíduos sólidos, moradores de bairros sem asfalto, velhos indígenas que caminham eternamente em trilhas pelas montanhas ${ }^{7}$ ). Uma curva de Lorenz representando a acentuação das desigualdades não suscita indignação moral.

O fundamento moral dessas políticas públicas focalizadas é ambíguo: nelas, é possíi vel enxergar uma moral da compaixão (é preN ciso em primeiro lugar participar da dor dos дं

N ${ }^{6}$ O prefácio do relatório do Banco Mundial de 1990 (p. 1) qualifica a pobreza como "aflitiva" e "infame". Referindo-se à filantropia da década de 1840, G. Procacci (1993,

ồ p. 175) escreveu: "a leitura moral da miséria foi uma cons-

tante no pensamento liberal desde seu início.” Em francês

"la lecture morale de la misère a été une constante de la pensée libérale dès ses débuts".

7 Os relatórios do Banco Mundial são um bom exemplo do que se fala, já que ilustram um discurso muito geral, macroeconômico na maior parte das vezes, de textos devidamente enquadrados que apresentam situações (Pedro o cortador de cana, Marta a favelada [...]) sob a forma de vitimização. pobres para tentar aliviá-la em seguida), uma moral da caridade, na qual se constata uma ausência da noção de equidade, e uma moral da justiça produtiva: a situação de equidade é aquela em que cada um recebe o que lhe é devido. Entretanto, é necessário que haja uma parte que se receba como devida no espaço da justiça produtiva, isto é, uma produção cuja contrapartida seja a remuneração do pobre. A boa política é, então, aquela que - via "empowerment dos pobres" e pelo desenvolvimento de suas capabilities - criará essa parte devida. A questão a considerar seria, então, a que se segue: seria admissível que um pobre, na condição de produtor, pudesse reclamar legitimamente aquilo que equivale à sua produção, teria como reclamar aquilo que é a condição de sua produção, isto é, os meios de produção? O sucesso (midiático, institucional e político) do microcrédito é a resposta adequada a essa indeterminação: é apresentado como "um beneficio para os pobres", ainda que nada lhes seja dado (e as taxas de juros sejam até mesmo superiores às aplicadas em empréstimos a grandes empresas); mas se inscreve em um registro moral: é uma medida paliativa de uma injustiça, de uma “exclusão" (bancária). Aparece, então, uma defasagem entre as políticas destinadas aos pobres "potencialmente produtivos" e as políticas destinadas aos "inúteis". Para os primeiros, fazse presente a dupla moral (como fundamento da intervenção daquele que oferece ajuda) e moralização (dos ajudados por sua inserção na esfera do trabalho). Essa dupla não opera unicamente no sentido da contenção; ela cria - se for utilizada a tese de Sen - espaços de liberdade, de subjetivação potencial.

Para os últimos, os "inúteis", só resta a moral, sem que seja produzida uma moralização caracterizada por uma ajuda pelo trabalho - e há um risco sempre presente de que ela suscite a reivindicação de um direito. A escapatória seria transformar esses "inúteis" em produtores de algum bem em particular: eles mesmos. É, portanto, como produtores de seu próprio capital humano (via educação ou 
saúde), que esses pobres serão legitimamente (no registro moral) ajudados, para, então, serem moralizados pelo trabalho sobre si mesmos (como produtores de seus corpos e de suas competências, certamente, mas também como bons pais, bons vizinhos, membros de "boas" comunidades). Mas essa saída não funciona para os "definitivamente inúteis" (os velhos ou deficientes, por exemplo); a moral da compaixão parece ser a única possibilidade de oferecer uma base para esse tipo de ajuda aos pobres, com o perigo constante de sofrer uma deriva em direção ao registro do Direito e dos direitos. ${ }^{8}$ Para conter essa possibilidade de deriva, é preciso, algumas vezes, "entrar na dança" e reconhecer efetivamente alguns direitos, ${ }^{9}$ desde que eles não se definam como universais. Os governantes preferem sempre os direitos atribuídos (top down) e inscritos no registro dos direitos humanos àqueles direitos conquistados (bottom up), assim como os direitos particularizados em relação aos direitos universais. Chega-se, assim, a esse paradoxo que marca as táticas atuais de governo: reconhecem-se direitos no âmbito do particular e do categorial em nome dos "direitos humanos", supostamente universais, para dar lugar a reivindicações universais desenvolvidas por categorias particulares.

A primeira onda de políticas focalizadas que se pôde encontrar em toda a América Latina consistiu no que se denominou de "políticas ultrafocalizadas", desenvolvidas ao

${ }^{8}$ O Benefício de Prestação Continuada, no caso brasileiro (criado em 1993 por uma "lei orgânica”), deu início a um "direito à assistência" a todas as pessoas idosas sem recursos e aos deficientes. Não se pode negligenciar o âmbito dessa assistência (um salário mínimo por beneficiário). As instituições internacionais pouco a evocam, preferindo enaltecer o Programa Bolsa Família, criado em 2003. No entanto, esse programa tem uma abrangência muito menor.

${ }^{9}$ Como, por exemplo, o fato de elevar a um nível "decente" (um salário mínimo) as aposentadorias rurais no Brasil, em 1991, exclusivamente em nome do fato de que esses velhos trabalhadores trabalharam por toda vida sem jamais ter contribuído com o pagamento da previdência. longo dos anos noventa, que visavam a uma categoria precisa: crianças de escolas de certo tipo de zona geográfica; mulheres grávidas desempregadas; pequenos camponeses situados a certo número de quilômetros dos lugares de comercialização, etc. As políticas foram objeto de críticas cada vez mais numerosas, inclusive no seio de organizações internacionais. Essas críticas destacaram duas esferas distintas:

- A primeira era de âmbito técnico: o dinheiro, de fato, ajuda os que são realmente pobres e, assim, seria possível uma relação comprovada entre a quantidade de recursos monetários investidos e o número de pessoas "que saíram da pobreza"? Por detrás desse nível "técnico", a determinação de "alvos" prioritários de auxílio coloca múltiplos problemas políticos e ideológicos. Por um lado, os alvos designados como prioritariamente mais "visíveis" são aqueles que têm mais peso político e aqueles que correspondem aos (pressupostos) a priori dos que estão encarregados de operar essas políticas. Seus efeitos constituem dimensões de moda, que impulsionam a priorização, em certos momentos, de algumas categorias de população (as mulheres, as crianças, os "indígenas") e, frequentemente, o esquecimento de outras categorias (trabalhadores idosos do meio urbano, certas categorias de working poor, em particular mulheres chefes de família). De outro lado, a vontade para minorar o problema - de confiar aos próprios pobres o cuidado de designar os alvos tende a delegar esse poder aos autoproclamados representantes que defendem os interesses de algumas categorias dotadas de um capital cultural e social, na medida em que fazem ouvir suas vozes; essas raramente são as categorias mais necessitadas.

- A segunda esfera é imediatamente "política"; trata-se da questão da eficácia em despolitizar a questão da pobreza. A base dessa despolitização é a disjunção de dois problemas: o problema da ajuda aos pobres e o problema da luta contra a pobreza. A ajuda aos pobres, fundada em uma moral da compaixão, passa primeiramente por técnicas que, na França, são denominadas de "trabalho social". A luta contra a pobreza passa, primeiramente, por técnicas macroeconômicas, encarregadas de promover o 
crescimento econômico. Essa disjunção dos dois registros (a moral do lado da assistência, a técnica do lado do crescimento) será posta em questão pela lenta, mas inexorável, tomada de consciência da necessidade de levar em conta a relação entre pobreza e desigualdades (que levará à "invenção" da noção de “pro-poorgrowth”); entretanto, a despolitização do debate sobre a pobreza tem o pressuposto de não relegar a moral ao domínio da assistência. É preciso também, de outro lado, passar por uma reformulação de sua dimensão macroeconômica e lhe dar um fundamento moral compatível com o discurso do mainstream. Descobre-se, então, a existência de desigualdades "demasiadamente importantes" - o que é, de uma só vez, moralmente condenável e prejudicial ao crescimento e, portanto, à redução da pobreza. O problema é que a moral nada tem a dizer dessa importância demasiada; a economia se torna, assim, a ciência das "boas" desigualdades.

O debate sobre a focalização ganhou as instituições internacionais a partir do fim dos anos noventa e, para acompanhá-lo, era necessário multiplicar as avaliações (bem como as publicações dos "manuais operacionais" para guiar os avaliadores em sua tarefa), curiosamente negligenciadas até então. ${ }^{10}$ Elas acabam resultando no questionamento de certos pressupostos, como aquele segundo o qual quanto mais precisa fosse a "focalização", menor seria o risco de malversação de recursos. Foi contestada particularmente a ideia segundo a qual a descentralização seria uma garantia de boa “focalização”. A colaboração entre poderes públicos e organizações não governamentais não garantiria mais as malversações por corrupção ela apenas muda seus beneficiários, acentuando as dificuldades de controle. Sem chegar a uma autocrítica radical, as avaliações chegam

${ }^{10}$ De forma confessa, o próprio Banco Mundial só tomou consciência desse processo em 1998, como testemunha esse extrato do Relatório Anual do meso ano (1999, p. 70 71): "As estratégias operacionais e as intervenções não foram sempre guiadas pelas avaliações da pobreza (...) [des-

de 1998] ao invés de contabilizar os projetos focalizados sobre a pobreza ele (O Banco Mundial) avalia o impacto dessas operações sobre os pobres e focaliza suas avaliações da pobreza nos resultados obtidos mais do que nos recursos postos em operação (como o montante de empréstimos ou o número de projetos)". geralmente na constatação em meio tom (do tipo: "chegamos a sucessos parciais, mas ainda resta muito a fazer; portanto vamos reiniciar as atividades").

As críticas das políticas "ultrafocalizadas" conduziram a uma mudança de "tática de governo dos pobres” em vários países latino-americanos, no final dos anos noventa e início dos anos dois mil. Essas críticas, todavia, não levaram a um questionamento da estratégia fundada sobre o tríptico moralização, tecnicização e despolitização da questão da pobreza, mas conduziram a uma mudança profunda dos encaminhamentos práticos das políticas públicas dessa luta, assim como a um ponto de inflexão: a substituição da "luta contra a pobreza" pela "luta contra a vulnerabilidade". Para além da definição técnica ou estatística, a vulnerabilidade indica uma mudança de registro: passa-se da compaixão vitimizadora (o pobre que recebe ajuda) à atenção paternal (o vulnerável que é ajudado a se ajudar e que é protegido enquanto continua frágil). Como já se notou muitas vezes, a retórica da vulnerabilidade está, mais do que a retórica da pobreza, em sintonia com o discurso de Amartya Sen e seu vocabulário (capabilities, empowerment, etc.). Entretanto, tanto uma como outra são herdeiras de dois "ramos" da moral cristã. Por um lado, o pobre ao qual se destina a compaixão do rico é o meio de sua salvação por meio da doação de esmolas. ${ }^{11}$ Por outro lado, a asserção "ajude a si mesmo e o céu o ajudará” - versão antiga da palavra de ordem da luta contra a vulnerabilidade - é uma constante do discurso religioso, mas também leigo, desde o final da Idade Média. ${ }^{12} \mathrm{~A}$ passagem à retórica da vulnerabilidade não diz respeito a nenhum sinal de não moralização (e ainda menos de uma re-

${ }^{11}$ Bronislaw Geremek cita essa “fórmula clássica” da Vida de Santo Elói (redigida por Santo Ouen no século VII): "Deus poderia tornar todos os homens ricos, mas quis que houvesse pobres nesse mundo para que o ricos pudessem redimir seus pecados.” (1987, p. 29).

12 Essa "moral" pode ser encontrada na fábula "Le chartier embourbé" de La Fontaine; mas ela remonta a Esopo, fabulista da antiguidade grega. $\mathrm{O}$ ditado deu origem ao nome de uma "sociedade jacobina" fundada em 1827, presidida por Guizot, que agrupava todos os liberais "progressistas” da época. 
politização) do debate; trata-se simplesmente da indicação da capacidade do discurso das instituições internacionais de entabular uma panóplia de argumentos morais, privilegiando aqueles que são adequados às técnicas da moda pelo fracasso das técnicas anteriormente utilizadas. ${ }^{13}$

O elemento mais significativo dessa mudança foi a invenção, multiplicação e popularização dos Programas de Transferência Condicionada de Renda (CCTP ou Conditional Cash Transfer Programs). Eles nasceram, em sua versão moderna, no México, com o Plano PROGRESA (1997), transformado, em 2002, no chamado Oportunidades. Em seguida, foram formulados os programas JJHD (homens e mulheres chefes de família sem emprego) na Argentina, Chile Solidário no Chile, Bolsa Família no Brasil e Familias en Acción na Colômbia e em dezenas de outros países. ${ }^{14}$

Todos esses Programas de transferência condicionada de renda (CCTP, Conditional Cash Transfer Programs) foram exaltados pelas instituições internacionais, especialmente o Banco Mundial e o Banco Interamericano de Desenvolvimento. ${ }^{15}$ Entretanto, esse entusiasmo não reside em atingir metas ou objetivos finais, que seriam os objetivos de longo prazo de saída da pobreza e melhora das condições de vida, que, no momento, não são nem observáveis nem mensuráveis. ${ }^{16}$ No curto prazo,

${ }^{13}$ O Prêmio Nobel atribuído a Yunnus acaba, então, por complementar o que tinha sido atribuído a Sen. Foi, assim, consagrado à desaparição da pobreza (em proveito da vulnerabilidade).

${ }^{14}$ Costa Rica, Equador, Honduras, Jamaica, Nicarágua, Panamá, Paraguai, Peru, República Dominicana, Uruguai. É possível encontrar, em texto de Enrique Valencia Lomelí (2008), uma apresentação de inúmeros detalhes desses planos.

${ }^{15}$ Por exemplo, em um longo documento sobre o Programa Bolsa Família, redigido por Kathy Lindert, Anja Linder, Jason Hobbs e Bénédicte de la Brière (2007), o Banco Mundial não cessa de fazer elogios; falando no prefácio do "interesse mundial" a respeito desse "laboratório", o documento saúda os responsáveis pelo ministério brasileiro de Desenvolvimento Social: "Estamos fortemente impressionados pelo seu engajamento, seu profissionalismo e sua excelência técnica. Realmente correram uma maratona como campeões tanto na concepção quanto na operacionalização do Programa Bolsa Família.” (p. 3).

${ }^{16}$ Ver o artigo citado de E. Valencia Lomelí: "no que concerne à redução da pobreza em longo prazo, não é possível medir os efeitos dos programas de transferência condicio- a pobreza diminui muito pouco: no México, o impacto do Progresa - Oportunidades, referente à redução da pobreza, é de $2 \%$ no meio rural e 7\% no meio urbano, em 2005. ${ }^{17}$ Por outro lado, na medida em que o nível de renda que dá direito ao benefício é muito baixo, a pobreza extrema diminui muito mais, ${ }^{18}$ assim como, consequentemente, os "bolsões de pobreza".

Uma característica notável da formação desse consenso em favor dos CCTP (Conditional Cash Transfer Programs) é sua rapidez: quando o Progresa tinha apenas três anos, em 2000, surgiu sua primeira avaliação (entusiasta, por sinal) pela International Food Policy Research Institute (IFPRI, organismo privado com base localizada em Washington). Os meios acadêmicos se engajaram rapidamente (as primeiras publicações datam de 2003) e os Bancos de Desenvolvimento (Banco Mundial e Banco Interamericano de Desenvolvimento) igualmente (a partir de 2005, nos seus relatórios anuais). Todavia, nem por isso a adoção desses planos ou programas resulta do efeito de uma "pressão" das instituições internacionais, já que respondem largamente a condições e pressões internas bastante diferenciadas conforme o caso. Mais do que uma imposição do exterior, o que se constata são as observações próprias da cada governo sobre as falhas das políticas sociais e, particularmente, das polí-

nada de renda no sentido estrito [...], mesmo entre os defensores da teoria convencional, alguns reconhecem que não há uma resposta à questão sobre o impacto sobre o bem-estar no longo prazo." Em francês: "En ce qui concerne la réduction de la pauvreté à long terme, les effets des CCTP ne sont évidemment pas encore mesurables au sens strict [...]. Même parmi les partisans de la théorie conventionnelle, certains reconnaissent qu'il n'y a pas de réponse aux questions concernant les impacts de long terme sur le bien-être." (2008, p. 498).

${ }^{17}$ De acordo com o estudo de Cortés, F., Banegas, I. e Solis, P. (2007).

${ }^{18}$ No Brasil, o conjunto das transferências condicionadas de renda (BCP, aposentadorias rurais e Bolsa Família) teria permitido, de acordo com estimativas realizadas a partir da PNAD (Pesquisa Nacional de Amostra de Domicílios, pesquisa sobre domicílios em termos de renda e consumo) de 2006, que o número de indigentes de 21,9 milhões (11,9 \% da população), seria de 38,9 milhões $(21,3 \%$ da população) na ausência desses programas (o que significa uma diminuição de 44,1 \%) (Pochmann, Abrahão, Cardoso, Soares, 2007, p. 18-21). Para os “pobres" sem adjetivação, as cifras eram, em 2004, de $31 \%$ com os programas de assistência e de $38 \%$ sem os programas de assistência (diminuição de 18 \%). 
ticas de assistência focalizadas; os constrangimentos e as pressões políticas são também muito diversos (períodos eleitorais, explosão social - como no caso Argentino, conflitos entre os diferentes níveis de governo), e os governos em curso parecem procurar, nas suas "caixas de ferramentas" assistenciais, aquilo que parece novo, pouco dispendioso e eleitoralmente produtivo.

O consenso em favor dos CCTP (Conditional Cash Transfer Programs) é amplo e polimorfo; reúne diferentes partidos em cada uma das cenas políticas nacionais, dos governos de cada país e das instituições internacionais, os governantes e a "sociedade civil" (se é que ela pode ser figurada pelas associações e ONGs, igrejas e sindicatos). Por outro lado, são raras as notas discordantes. Certos analistas acentuam o caráter módico das despesas públicas ligadas aos CCTP e sugerem que seria possível reconhecer, nesses programas, uma operação de propaganda mais do que uma política social: os CCTP não implicam reforma da distribuição primária de renda, nem transformam os sistemas tributários. Outros insistem no fato de que os aspectos "produtivos" desses programas ("produção de capital humano") são puramente retóricos (na medida em que a oferta de serviços públicos não os acompanha) e, de todo modo, só seriam observáveis, no mínimo, ao longo de uma geração. Mas, de modo global, essas críticas são discretas. Domina o consenso, o que conduz à ideia de uma forte legitimidade desses programas.

As razões da formação desse consenso, apesar da ausência de resultados decisivos e mensuráveis relativos à diminuição da pobreza, podem ser sintetizadas como se segue:

- Paradoxalmente, eles parecem melhor "focalizados" do que as políticas "ultrafocalizadas", ainda que com uma definição um pouco limitada dessa "focalização": há poucos "não pobres" que recebem os auxílios. Por outro lado, parece que há um número significativo de "pobres" (de acordo com uma definição a partir dos critérios de atribuição dos auxílios), cerca de um quarto, segundo a maior parte das avaliações, que não são assistidos..$^{19}$ Mas isso não parece ser muito grave; talvez o montante de pobres não auxiliados possa ser explicado pelas seguintes razões: poderiam estar entre os falsos pobres, ou ainda ser beneficiários de solidariedades incomuns - familiares e religiosas -, ou ainda, estupidamente, recusar a indagação dos controles ou a estigmatização que existe apenas na sua fantasia. Também é possível que haja problemas técnicos, mas eles vão se resolver: a informação se difunde e a malha administrativa se intensifica.

- Os CCTP não custam caro (de 0,1 a 0,9\% do PIB, de acordo com os países, ou seja, muito menos do que, por exemplo, os déficits da previdência pública) e têm um peso grande em termos políticos: há um vínculo muito positivo entre a extensão desses programas e os votos favoráveis ao governo que os institui (o que é particularmente claro no Brasil, no final de 2006, mas igualmente presente no Chile e na Argentina), além do impacto em termos de "imagem" no plano internacional.

- Os CCTP não foram vítimas da "síndrome de Speenhamland". ${ }^{20}$ Um desestímulo ao trabalho é limitado, essencialmente porque esses programas não tinham por objetivo a reinserção pelo trabalho. As únicas condições realmente controladas foram as con-

${ }^{19}$ Lindert, Linder, Hobbs e de la Brière (2007) consagraram muita páginas à questão do "targeting" para concluir que "o Programa Bolsa Família é extremamente focalizado", observando, em particular, que o quartil de menor renda recebia $80 \%$ dos auxílios e que $85 \%$ dos $20 \%$ pagos indevidamente (the leakages) eram destinados ao quartil seguinte (p. 46) Pode-se notar que outro aspecto da má "focalização", isto é, a proporção das famílias pobres que não recebem o auxílio do Bolsa Família foi abordado em apenas quatro linhas desse documento (p. 47). A caça aos "falsos pobres" parece dominar as preocupações, apesar de se mencionar que "nem todos os pagamentos indevidos (leakages) provêm de fraude" (nota 78); as fraudes intencionais foram estimadas em $7 \%$ do total de beneficiários (p. 74).

${ }^{20}$ Comentando os efeitos do Speenhamland Act de 1975 que instaurava uma renda mínima complementar, Karl Polanyi (1984) escreveu (p.116): "Nunca uma medida foi tão universalmente popular [...]: os humanistas aplaudiram a medida como um ato de misericórdia ou mesmo de justiça [...]; e, todavia, 'a longo prazo o resultado foi horrível' gracas à baixa de produtividade que resultou do desestímulo ao trabalho, da baixa dos salários que se seguiu e da alta dos impostos destinados a financiar o socorro. Em francês: "Jamais mesure ne fut plus universellement populaire [...]; les humanitaristes applaudissaient la mesure comme un acte de miséricorde, sinon de justice [...]"; et pourtant "à la longue, le résultat fut affreux", en raison de la baisse de la productivité due à la désincitation du travail, de la baisse des salaires qui s'en est suivie et de la hausse des impôts destinés à financer les secours. 
dições de assistência escolar às crianças e alguns exames médicos (em particular, os exames da fase pré-natal). Além disso, o Banco Mundial, na falta de poder demonstrar os efeitos desses programas no que se refere à luta contra a pobreza, congratulase, antes de tudo, com seus resultados em termos de escolarização. Os CCTP são bem sucedidos, portanto, porque atingem objetivos diversos daqueles que tinham sido proclamados.

- Os CCTP liberam os pobres. Todos os programas anteriores de luta contra a pobreza foram atacados em função da questão de enclausuramento na dependência dos pobres e de sua estigmatização. Esses programas lhes dão toda liberdade de uso dos recursos monetários obtidos. Haveria, assim, evidentemente, algumas restrições, em particular no caso mexicano, já que o pagamento do dinheiro às mães permite destacar explicitamente uma desconfiança em relação ao uso que os pais poderiam fazer desses recursos. Entretanto, de um modo global, trata-se de uma estratégia de empowerment dos pobres: permitindo-lhes acessar um nível de recursos que ultrapassa a estrita necessidade alimentar e possibilitando que façam escolhas econômicas. E mais: deposita-se confiança para que façam seus cálculos racionais; a razão e a moral podem, enfim, ser conciliadas, já que os pobres podem, finalmente, mostrar que podem, eles também, constituir-se como homines economici. ${ }^{21}$ Entretanto, é impossível mensurar os efeitos dessa estratégia de empowerment. $\mathrm{O}$ que as avaliações mensuram são as melhorias em relação direta com as condições de acesso: melhora das taxas de matrícula e frequência escolar nessa e naquela idade; redução das intercorrências de saúde pré e perinatais. Esses objetivos são moralmente incontestáveis, e a melhora dos indicadores valida a fundamentação desses programas. Mas, quando se sai dos serviços diretamente ligados às condições de acesso, as coisas são menos claras. É provável que tenha havido uma melhora das situações mais severas de desnutrição, de má

${ }^{21}$ Ver Braun e Chudnovsky (2005), autores que desenvolvem a ideia segundo a qual os pobres são definidos como capazes de efetuar cálculos, a partir da relação racional custo-benefício. nutrição e de anemia. ${ }^{22}$ Mas, uma vez que se atinge esse patamar mínimo alimentar, não se sabe muito o que os pobres fazem com o dinheiro que lhes é dado. Supõe-se, portanto, que sejam racionais.

- Os CCTP produzem bastante legitimidade. O governo "faz qualquer coisa pelos pobres”, massivamente, e não a conta-gotas; ${ }^{23}$ o governo resiste às pressões do financiamento internacional e desenvolve políticas sociais (como no caso da Argentina); o governo encara o braço de ferro da questão do apartheid mascarado do qual são vítimas os indígenas e os reinsere na sociedade (como no México). Sem que a categoria "povo" desempenhe um papel mais significativo, ela acaba por se apresentar não apenas no sentido do populismo original dos anos 1940, mas no sentido da "coesão social”, de um corpo coletivo que garante, sob a liderança benevolente do Estado, a reincorporação dos que foram deixados, por sua própria conta, como cidadãos sem cidadania.

\section{CONSENSO E MALENTENDIDO}

Essa paixão generalizada pelos programas de transferência condicionada de renda se cala em torno de um consenso no seio das organizações internacionais; e esse consenso é periodicamente celebrado nas "International Conferences on Conditional Cash Transfers". ${ }^{24}$ Entretanto, esse consenso pode ser visto com suspeição. Com efeito:

- Em longo prazo, os resultados dos CCTP sobre a pobreza são desconhecidos; em curto prazo, pode-se afirmar que há uma diminuição da pobreza estrema, mas sem garantia de que ela seja definitiva (portanto, sem garan-

${ }^{22}$ E. Valencia Lomelí (2008, p. 494) cita 13 estudos que vão nessa direção, particularmente em relação ao México, Nicarágua, Colômbia e Brasil.

${ }^{23}$ É significativo que, no caso do Bolsa Família brasileira, esse caráter massivo seja imediatamente ilustrado pelo número muito elevado de beneficiários (quase 12 milhões de famílias, ou seja, perto de 50 milhões de pessoas) e não pelo custo bastante baixo (0,4\% do PIB).

${ }^{24}$ São organizadas bienalmente (no México em 2002, no Brasil em 2004 e na Turquia em 2006) pelo Departamento de Proteção Social e Gestão de Riscos (Social Protection and Risk Management) do Banco Mundial; na chamada dessas conferências, encontra-se repetidamente a fórmula "There is clear evidence of success [...]". 
tia de uma diminuição da vulnerabilidade).

- Esses "novos" programas de ajuda aos pobres são muito diversificados. Há uma unanimidade a seu favor, mas ninguém sabe se o que se está falando tem exatamente o mesmo significado. Essa maleabilidade é o signo de sua capacidade de adaptação aos imaginários coletivos locais ${ }^{25}$ e se constitui, em alguma medida, na condição de seu sucesso. Ao mesmo tempo, essa maleabilidade torna difícil o estabelecimento de um catálogo mundial de "boas práticas".

- O discurso das instituições internacionais passa sem mediações do consenso em favor dos programas de transferência condicionada de renda à sua legitimidade. Ora, se acompanharmos Jacques Rancière, o consenso acaba por se referir a si mesmo, tornandose autorreferente: ${ }^{26} \mathrm{o}$ consenso não produz frações. Ele pesa sobre o todo e cada uma de suas partes. O consenso não é apenas um "senso comum", mas um compartilhar do sentido do todo; funda sua autoproclamação de legitimidade decretando ilegítimas todas as opiniões que não encontram lugar no interior desse campo consensual.

O problema é que tal autoproclamação repousa sobre um argumento moral. Ora, desde Max Weber, é possível saber que a moral é insuficiente para fundar, por si mesma, a legitimidade; com efeito, os sistemas de valores são particulares e diversos, e não há uma regra

${ }^{25}$ Por exemplo, a instância do Programa argentino (PJJHD) * de reinserção pelo trabalho assalariado (mesmo que isso

亏 seja largamente fictício) faz referência a um imaginário coletivo no qual o trabalhador assalariado (e portador dos j direitos de um trabalhador) continue sendo a matriz da @ figura do cidadão; ao mesmo tempo, no Brasil, o cidadão ¿ é primeiramente portador de direitos que ele pode fazer $\bowtie$ valer em relação ao Estado, qualquer que seja seu estatuto - como trabalhador, o que faz com que a noção de "direito 千 à assistência” faça sentido, enquanto, na Argentina, ela é uma redundância absurda que reforça a estigmatização.

26 "O que o consenso quer dizer, com efeito, não pelo acor-

i do das pessoas entre si, mas o acordo do sentido com o N sentido: o acordo entre um regime sensível de apresen-

¿ tação das coisas e um mundo de interpretação de seus - sentidos [...] O consenso diz que há apenas uma única

సิ realidade cujos sentidos é preciso esgotar, um só espaço, $>$ cujas fronteiras não é preciso delinear, um só tempo, cujas fi figuras não se multiplicam. Em consequência, não há ou- tra exigência a não ser consentir.” Em francês, conforme citação original: "Ce que consensus veut dire en effet, ce ก n'est pas l'accord des gens entre eux, mais l'accord du sens - avec le sens: l'accord entre un régime sensible de présentation des choses et un mode d'interprétation de leur sens. [...] Le consensus dit qu'il n'y a qu'une seule réalité dont i faut épuiser les signes, qu'un seul espace, quitte à y retracer les frontières, qu'un seul temps, quitte à en multiplier les figures. En conséquence de quoi il ne nous demande que de consentir." (Rancière, 2005a, p. 8 et 10) moral que possa oferecer fundamento para a legitimação de uma moral face à outra. Só um sistema de normas exterior à moral, o direito, pode desempenhar esse papel que possibilite essa justaposição federada (entre uma moral e sua legitimação). Seria, portanto, necessário, para fundar a legitimidade universal dos auxílios aos pobres, inscrevê-los no registro dos direitos. Entretanto, depois de dois séculos, a assistência aos pobres opera sobre um constrangimento absoluto: escapar do registro do direito positivo. ${ }^{27}$ Os CCTP, assim como as "políticas focalizadas”, não escapam a esse imperativo. Assim, duas etapas precisam ser percorridas: primeira, postular a universalidade da moral, em nome da qual os pobres utilizam a mesma retórica que aqueles que os auxiliam para se inscrever nos mecanismos da ajuda. E, em segundo lugar, fazer admitir que é a moral que funda os direitos "humanos", os "direitos da liberdade", que podem substituir a "reivindicação de direitos", obrigações positivas do Estado em relação aos cidadãos que constituem os pobres. ${ }^{28}$

O fato, entretanto, de os pobres utilizarem a mesma retórica moral que os benfeitores permite postular que existe um consenso sobre os valores que fundam essa moral, já que o que se afirma é a racionalidade econômica dos pobres e, assim, sua provável aptidão para aproveitar as “ofertas”. Surgiu, então, a hipótese de um mal-entendido. Trata-se da pergunta:

27 Giovanna Procacci comentou também, a propósito da França dos anos 1840: "A assistência legal tem também o efeito inevitável de desencorajar a reforma dos costumes, que deveria, ao contrário, ser a visada real de uma política de assistência. Definitivamente é verdade que a assistência é um dever da sociedade e a esse dever não corresponde - o que é excepcional e paradoxal - nenhum direito do cidadão". Em francês, conforme o original: "L'assistance légale a ainsi l'effet inévitable de décourager la réforme des mœurs, qui doit être en revanche la visée réelle d'une politique d'assistance. En définitive, s'il est vrai que l'assistance est un devoir de la société, à ce devoir ne correspond, fait exceptionnel et paradoxal, aucun droit du citoyen" (1993, p. 229).

${ }^{28}$ Cf. Olivier Corten (2002, p. 198): "O direito formaliza não apenas um projeto político federativo, mas também valores comuns cujo respeito parece ser indispensável à sociedade. O exemplo dos direitos do homem é certamente particularmente significativo dessa jurisdicização da moral". Em francês: "Le droit formalise non seulement un projet politique fédérateur, mais aussi des valeurs communes dont le respect apparaît indispensable à la société. L'exemple des droits de l'homme est certainement particulièrement significatif de cette juridicisation de la morale”. 
os benfeitores e os beneficiários, os que ajudam e os que são ajudados compreenderiam, na realidade, apenas uma coisa: a ajuda? Lena Lavinas (2007, p. 60) fez essa sugestão a propósito do Programa Bolsa Família no Brasil. Os pobres sabem muito bem que, apesar das proclamações do presidente (Lula), "eles que tinham o hábito de serem considerados como não cidadãos ou cidadãos de segunda classe", e não se tornaram "verdadeiros cidadãos" pelo único fato de receber uma alocação que corresponde a, no mínimo, um quarto do salário mínimo por cabeça. Não se trata propriamente de falar de um direito vinculado à cidadania, mas da escolha do "menos pior". Aqui reside o elemento principal da autofocalização: aceitam-se os custos impostos, porque seria pior, mais custoso, não aceitá-los.

Essa é a moral dos pobres "beneficiários" dos auxílios. Eles o tomam sem constrangimento e, além do mais, não estão satisfeitos. Desde a filantropia dos anos 1820, a questão estava colocada nos termos que se seguem: como fazer com que os pobres tomem em conjunto o auxílio e a moral que o acompanha, nossa moral de benfeitores? Não há - a propósito da América Latina - nada a alterar ou acrescentar às numerosas passagens do L'argent des pauvres de Jean-François Laé e Numa Murard; essa passagem, por exemplo: "o auxílio em dinheiro ou em espécie [...] nada mais era do que o pretexto para uma intervenção educativa ou reeducativa. Nada é gratuito; o dinheiro é acompanhado pela moral. Há uma tensão permanente que transparece nos relatos, entre os objetivos educativos e os objetivos financeiros dos auxílios. Os Blanchardins (nome dos habitantes do conjunto de abrigo provisório onde foi realizada a pesquisa) aceitam e mesmo reivindicam massivamente os auxílios, mas vomitam a moral e os modos de vida com os quais são bombardeados conjuntamente. São assistidos economicamente; mas não se deixam facilmente assistir no plano psicológico ou moral. Portanto, se aproveitam (Laé; Murard, 1985, p. 178-179)."
Os pobres podem ser qualificados, de acordo com o julgamento de cada um, como cínicos ou pragmáticos: "Pode-se encontrar, frequentemente, um discurso contraditório entre os próprios destinatários do auxílio: criticam a natureza assistencial das intervenções públicas, mas, ao mesmo tempo, desenvolvem estratégias diversas para se beneficiar desses programas assistenciais e, no momento de formular suas demandas, é provável que deixem de lado muito de suas objeções: 'pouco importa de onde vem o auxílio, o importante é que ele vem'29". Os benfeitores acabam por proclamar sua fadiga em ajudar (aid fatigue): todos os discursos sobre reabilitação, a moralização, o ingresso no mercado de trabalho dos pobres se chocam com essa alteridade fundamental: eles não são como nós (os benfeitores), seres morais. Os benfeitores gostam de ajudar os pobres; os pobres não apreciam senão os auxílios e fingem gostar dos benfeitores.

Para sair dessa aporia do debate sobre a moral (e a armadilha), é necessário evocar uma evidência já magistralmente analisada por Simmel: os pobres nada são "além" de pobres, até mesmo do ponto de vista das políticas públicas. De um lado, como beneficiários de programas de auxílio aos pobres, são criados como pobres: "Por causa dessa falta de qualificação positiva, a classe dos pobres [...] não engendra, apesar de sua posição comum, forças sociologicamente unificadoras. Nesse sentido, a pobreza é um fenômeno sociológico único: certo número de indivíduos que, além de um destino puramente individual, ocupam uma posição orgânica específica no interior do todo; mas essa posição não é determinada por esse destino e essa condição, mas antes pelo fato de que os outros - indivíduos, associações, comunidades - ten-

${ }^{29}$ Ver Lumi, Golbert, Tenti Fanfani (1992, p. 11). Também na conclusão (p. 157), a propósito da "percepção muito particular da política como prática” que os assistidos possuem, esses autores acrescentam: "certo pragmatismo aconselha que, face às promessas não cumpridas, é preciso exigir que os políticos 'paguem' adiantado o apoio que solicitam das pessoas". Em francês: "un certain pragmatisme conseille que, face à tant de promesses non tenues, il faut exiger des politiciens qu'ils 'payent' d'avance l'appui qu'ils sollicitent des gens". 
tam retificar essa condição. Assim, não é a falta de meios que torna alguém pobre. Sociologicamente falando, a pessoa pobre é o indivíduo que recebe assistência por causa dessa falta de meios" (Simmel, 1998, p. 101-102).

Mas, de outro lado, os pobres não são somente os "beneficiários" dos programas de luta contra a pobreza. São, também, objeto de múltiplas políticas, tanto na América Latina como em outros contextos: políticas de educação, políticas de saúde, políticas de infraestrutura e equipamentos urbanos, políticas de emprego, políticas culturais, etc. $\mathrm{O}$ fato de que o benefício de algumas políticas públicas seja condicionado a um nível de renda (means tested) em nada impede que seja como cidadão em idade escolar que "o pobre" se beneficiará das políticas educativas, e que seja como cidadão doente que ele será cuidado, etc. Assim, as políticas de distribuição condicionada de rendimentos por um patamar de renda não são, em si mesmas, políticas estigmatizantes de luta contra a pobreza, na medida em que não são politicamente construídas como tal.

Elas não parecem ter sido estigmatizantes até o final dos anos 1980. Assim, as políticas espacializadas em relação às periferias urbanas (provimento de água e esgoto, eletrificação, habitação) eram manifestadamente * destinadas principalmente aos "pobres", assim ลิ como as políticas de ajuda à agricultura familiar, sem que, por isso, fossem políticas de luta contra a pobreza. Seu fundamento não era o tratamento de uma forma de "governo" específico a uma categoria criada ao mesmo tempo em que se instaura essa prática, mas uma i problemática de integração em uma dinâmica a social global e, portanto, de produção de cidadania. O fim dos anos 1980 marca, desse ponto de vista, uma profunda mutação; não há mais pessoas que são pobres e que vão se beneficiar eventualmente de políticas (urbanas, de preços da alimentação) específicas, mas uma categoria de "pobres" que foi criada, de acordo com o esquema simmeliano, pelo fato mesmo de designar essas políticas como "políticas de luta contra a pobreza".

A "virada" dos anos 1990 reside essencialmente no que se segue: a criação de uma categoria, os pobres, que são tanto mais legitimamente os objetos de auxílio que se lhes atribui quanto mais se tem em conta que é esse auxílio que os cria. Polarizando todas as políticas sociais na questão da ajuda aos pobres (não se generaliza a educação primária; promove-se a escolarização de crianças pobres; não se cria um sistema generalizado de saúde de base; promove-se o acesso dos pobres à saúde; não se providencia a construção de equipamento de esgotamento sanitário nos bairros periféricos: promove-se o saneamento dos bairros pobres, etc.), elimina-se uma noção forte (os direitos sociais) em benefício de uma noção mais do que fraca: trata-se de uma noção vazia. Essa operação é, em si mesma, uma operação de despolitização. E, voltando para uma definição rancieriana do consenso, uma noção que "nada nos pede além de consentir"; trata-se, então, da instauração de uma hegemonia consensual. O paradoxal é que esse consenso repouse sobre o mal entendido constitutivo revelado por Simmel: a pobreza só tem substância própria para aquele que não é pobre.

Esses elementos colocam a questão da definição de uma eventual despolitização da questão social; ela repousa, em primeiro lugar, na capacidade de fazer tudo para evitar a junção entre o problema dos pobres, que se cria pelo tratamento que recebe, e a questão dos direitos e da cidadania, de deixar a "tensão" subsistir apenas por sua contenção. O exemplo brasileiro é particularmente interessante desse ponto de vista: hoje, o benefício de prestação continuada (BPC) tem existência legal, mas, nas representações comuns, considerado como um direito do cidadão, ele é irreversível e sem contrapartida específica. A Bolsa Família, por sua vez, não se constitui juridicamente em "direito do cidadão", e o governo poderia suprimi-la ou reajustá-la, pelo menos a qualquer momento. Mas isso coloca a questão da definição de uma eventual despolitização da questão 
social; ela se recoloca. Vê-se bem a impossibilidade política de tal supressão, assim como a impossibilidade de escapar da sombra da filantropia liberal: que os pobres considerem o auxílio como algo devido, como um direito adquirido (un dû) e recusem legitimamente toda contrapartida. A "tática de governo" repousa, então, sobre o fato da constatação, da concessão, polarizando o debate sobre essa questão para esvaziar o que lhe é essencial: a questão da repartição primária de renda, a dimensão fiscal e a oferta de serviços públicos.

"Constatar" não significa, entretanto, que os direitos assim reconhecidos sejam proclamados ou reivindicados "contra" ou "face a" qualquer sujeito político. As mudanças na "arte de governar os pobres", depois de uns dez anos, tendem, de modo paradoxalmente aparente, a lhes apresentar como direitos absolutos, como direitos "humanos", sem oposição possível, porque não haveria ninguém - sobretudo o Estado - que lhe faria oposição. A passagem para uma focalização ampla e para a distribuição de alocações por rendimento, abordadas em nome dos "direitos humanos", delimita dois espaços bem distintos: o das técnicas e dos técnicos (em educação, em saúde, em vias de tráfico, etc.), em que a política não tem lugar, e o espaço dos "direitos humanos à renda mínima”, em que a política tem o maior quinhão, já que há apenas um protagonista, o Estado "moral", que se transforma em portavoz dos que "não têm voz", ao mesmo tempo em que essa voz se endereça àquele que a retransmite sem cessar, em um jogo de abismos sem fim. O círculo se completa, ao mesmo tempo em que o mal-entendido permanece e que esse mal-entendido se torna a cinza sob a qual arde a política.

\section{CONCLUSÃO: as pequenas falhas da polícia}

Podem-se ler alguns trabalhos recentes de Jacques Rancière de modo pessimis- ta: querendo caracterizar a democracia como uma "pérola rara" e chegando a duvidar que ela possa ocorrer a não ser em momentos imprevistos e a partir de um surgimento breve e pouco efetivo. De modo geral, a política é obstaculizada e reina a despolitização: "despolitizar, esse é o velho trabalho da arte política, aquele que se conclui do começo ao fim, cuja perfeição se encontra na borda de seu esvaziamento." (Rancière, 1998, p. 47). Essa leitura, no entanto, passa ao largo do essencial: a política não está no âmbito dos acontecimentos, mas da tensão. A política está sempre lá, em tensão com a "polícia", ${ }^{30}$ e as políticas públicas não são apenas "polícia".

As políticas públicas de luta contra a pobreza, na América Latina, são ambivalentes e ambíguas, mas não são um eterno recomeçar. Elas não podem existir senão por essa tensão constitutiva que as fez nascer e se transformar, permanentemente, em um percurso sinuoso muitas vezes regressivo (em particular nas fases de ditadura ou por ocasião da ofensiva neoliberal no começo dos anos 1990), cuja direção geral, entretanto, é a afirmação de uma consciência comum dos direitos da cidadania. Mesmo se esse percurso não corresponde ao que Rancière chamou de democracia, ${ }^{31}$ "a sociedade igual (que) é o conjunto das relações igualitárias que se desenham aqui e agora através de atos singulares e precários" (Rancière, 2005b,

30 Jacques Rancière, referindo-se a Michel Foucault (1994b), definiu a palavra "polícia” em La mésentente (Rancière, 1995, p. 51): “Chamamos geralmente política o conjunto de processos pelos quais se operam a agregação e o consentimento das coletividades, a organização dos poderes, a distribuição dos lugares e funções e os sistemas de legitimação desta distribuição. Proponho dar outro nome a essa distribuição e ao sistema dessas distribuições. Proponho chamá-los polícia.” Em francês: “On appelle généralement du nom de politique l'ensemble des processus par lesquels s'opèrent l'agrégation et le consentement des collectivités, l'organisation des pouvoirs, la distribution des places et fonctions et les systèmes de légitimation de cette distribution. Je propose de donner un autre nom à cette distribution et au système de ces distributions. Je propose de l'appeler police".

31 “(A democracia) é a ação que arrebata sem trégua dos governos oligárquicos o monopólio da vida pública e a riqueza da potência total sobre as vidas". Em francês: " [La démocratie] est l'action qui sans cesse arrache aux gouvernements oligarchiques le monopole de la vie publique et à la richesse la toute-puissance sur les vies" (Rancière, 2005b, p. 105). 
p. 106), talvez se possa dizer que ele pode estar em germe nesses direitos sociais que as políticas públicas criam inadvertidamente. A uma interpretação pessimista de Jacques Rancière seria possível opor uma visão mais otimista: a de que pequenas falhas fissuram a "polícia" e que, por elas, a política pode se infiltrar.

Recebido para publicação em 19 de setembro de

\section{REFERÊNCIAS}

BANQUE MONDIALE. La pauvreté, rapport sur le développement dans le monde. Washington D. C.: Banque Mondiale, 1990.

Rapport sur le développement dans le monde 1998 Washington D. C.: Banque Mondiale, 1999.

BRAUN, Miguel; CHUDNOVSKY, Mariana. Transferencias condicionadas enefectivo como estrategia de reduccion de la pobreza: unstudiocomparativeen América Latina. Washington D. C.: BID, Dialogo Regional de politica: Red para lareduccion de la pobreza y laproteccion social, 2005.

CORTEN, Olivier. La persistance de l'argument légaliste: éléments pour une typologie contemporaine des registres de légitimité dans une société libéral Droit et société, Paris, n. 50, p. 185-208, jan-abr., 2002.

CORTÉS, Fernando; BANEGAS, Israel; SOLIS, Patricio. Pobres con oportunidades, Mexico 2002-2005. Estúdios Sociologicos, Mexico, v. 25, n. 73, p. 3-40. 2007.

FOUCAULT, Michel. La gouvernementalité. In: FOUCAULT, M. Dits et écrits, tome 3, Paris: Gallimard, p. 635-657, 1994a.

Omnes et singulatim: vers une critique de la raison politique. In: FOUCAULT, M., Dits et écrits, tome 4, Paris, Golitique. In: FOUCAULT, M.,

GEFFRAY, Christian. Chroniques de la servitude en ง่ Amazonie brésilienne. Paris: Karthala, 1995.

GEREMEK, Bronislaw. La potence ou la pitié: l'Europe et ¿ les pauvres du Moyen-Âge à nos jours. Paris: Gallimard, ๘ 1987.

N

LAÉ, Jean-François; MURARD, Numa. L'argent des pauvres, §ิ La vie quotidienne en cité de transit. Paris: Seuil, 1985

¿. LAUTIER, Bruno. L'État-providence en Amérique latine: i utopie légitimatrice ou moteur du développement? In

^ MARQUES, Pereira B. (dir.). L'Amérique latine: vers la

¿ démocratie?, Bruxelles: Éditions Complexe, p. 97-128, N 1993.

Les malheureux sont les puissants de la Terre.. Représentations et régulations étatiques de la pauvreté en Amérique latine. Revue Tiers Monde, Paris, n. 142, p. 383409, 1995

路

LAVINAS, Lena Transferências de renda: o "quase tudo" ت̃ do sistema de proteção social brasileiro. In: SICSÚ, J. 寽 (dir.), Arrecadação (de onde vem?) e gastos públicos (para onde vão?). São Paulo: Boitempo Editorial, 2007.

LINDERT, Kathy; LINDER, Anja; HOBBS, Jason; BRIÈRE, Bénédicte de. The nuts and bolts of Brazil's Bolsa Familia
Program: inplementing conditional cash transfers. In: $A$ decentralized context, social protection discussion paper. n. 0709, mai, Washington D. C.: The World Bank, 2007.

LOMELÍ, Enrique Valecia. Conditional cash transfers as social policy in Latin America: An Assessment of their Contributions and Limitations. In: Annual Review of Sociology, v. 34, p. 475-499, 2008 LUMI, Susana; GOLBERT, Laura; TENTI, Fanfani Emilio.
La mano izquierdadel Estado, La asistencia social según los benficiarios. Buenos Aires: Ed. Miño y Dávila/Ciepp, 1992.

POCCHAMANN, Marcio; ABRAHÃO, J.; CARDOSO, J. C.; SOARES, S. (dir.), PNAD 2006, Primeiras Análises: demografia, educação, trabalho, previdência, desigualidade de renda e pobreza. Brasília/Rio de Janeiro: IPEA, 2007

POLANYI, Karl. La grande transformation. Paris: Gallimard, 1984.

PORTE, D.; CRAIG D. Third Way for the Third World: Poverty Reduction, Social Inclusion and the Rise of "Inclusive" Liberalism. Review of International Political Economy, Toronto, York University, v. 11, n. 2, p. 387-423, 2004.

PROCACCI, Giovanna. Gouverner la misère: la question sociale en France, 1789-1848, Paris: Seuil, 1993.

RANCIÈRE Jacques, La mésentente. Paris: Éditions Galilée, 1995. $\overline{1998}$

Aux bords du politique. Paris: La Fabrique Éditions, . Chronique des temps consensuels. Paris: Seuil, 2005a. 2005b.

La haine de la démocratie. Paris: La fabrique Éditions,

SIMMEL, Georg. Les pauvres. Paris: PUF, 1998. 


\section{THE MORAL GOVERNMENT OF THE POOR AND THE DEPOLITICIZATION OF PUBLIC POLITICS IN LATIN AMERICA}

\author{
Bruno Lautier
}

As a starting point, the text bring the idea that Latin America has been living, over the last two decades, a tension between two discourses, two world views and ways of building a society: on the one hand, the verification of dysfunctions which should be corrected, and on the other hand the claims and demands in the name of citizenship, of rights, and of their universalization. The hypothesis is that this tension - lessened, but not extinct - and its unfolding have strong relations with the conception, institution, management, and operationalization of social policies, in a trajectory that goes from the developmental point of view to the processes of focalization, and the rights to the moral government of poverty and its unfolding.

KEYwORDS: Social policies. Rights. Citizenship. Latin America. Moral.

\section{LE GOUVERNEMENT MORAL DES PAUVRES ET LA DÉPOLITISATION DES POLITIQUES PUBLIQUES EM AMÉRIQUE LATINE}

\author{
Bruno Lautier
}

Le point de départ de ce texte est basé sur l'idée que l'Amérique Latine allait vivre au cours des deux dernières décennies une tension entre deux discours, perceptions du monde et manière d'élaborer la société: d'une part la constatation de disfonctions qui doivent être corrigées et d'autre part les revendications et les exigences faites au nom de la citoyenneté, de droits, de leur universalisation. L'hypothèse est que cette tension - aménisée mais non pas éliminée - et ce qui en découle sont en lien direct avec la conception, l'institution, la gestion, la mise en oeuvre de politiques sociales tout au lon d'un parcours qui va de l'accent mis sur le développement aux processus de mise en évidence des droits au gouvenement moral de la pauvreté et leurs conséquences.

Mots-CLÉs: Politiques sociales. Droits. Citoyenneté. Amérique Latine. Morale. 
